\title{
Análise de uma experiência híbrida no ensino de Física 1
}

\author{
Analysis of a blended experience on Physics 1 teaching \\ Fábio Ferreira Monteiro*1@ \\ ${ }^{1}$ Universidade de Brasília, Instituto de Física, Brasília, DF, Brasil.
}

\begin{abstract}
Recebido em 27 de julho de 2020. Revisado em 05 de novembro de 2020. Aceito em 23 de novembro de 2020
Este artigo apresenta uma análise da percepção dos estudantes sobre uma experiência de ensino híbrido, desenhada e aplicada nas disciplinas básicas de Física 1 de 18 cursos diferentes na Universidade de Brasília. Uma pesquisa de opinião, utilizando escala tipo-Likert, foi elaborada e utilizada para estimar o grau de concordância dos estudantes com proposições afirmativas relativas à organização da disciplina, potencial de aprendizagem e qualidade do sistema de avaliação. Os resultados revelaram boa concordância com as proposições apresentadas, e indicaram que, na opinião dos estudantes, os fóruns on-line foram importantes no processo de aprendizagem. Contudo, apontou também algumas necessidades, como: (a) intervenções que possam estimular a inclusão dos estudantes menos proficientes; (b) atividades que possam influenciar estes estudantes a desenvolver motivação para o aprendizado; e (c) reflexões sobre as regras das avaliações formativas e somativas, que possam transformar o aspecto punitivo em uma forma de mediação na composição das menções finais dos estudantes.
\end{abstract}

Palavras-chaves: Ensino híbrido, fóruns on-line, interação entre pares, escala tipo-Likert.

This paper presents an analysis of the students' perception of a blended learning experience, designed, and applied in the basic disciplines of Physics 1 of 18 different courses at the University of Brasilia. An opinion survey, using a Likert-type scale, was designed, and used to assess the students' agreement degree with affirmative propositions related to the organization, learning potential, and quality of the evaluation system. The results showed good agreement with the presented propositions, and the importance of the positive role of the online forums in the learning process by promote student-student and student-monitor dialogic interaction. However, it also pointed out some needs, such as (a) interventions that can stimulate the inclusion of less proficient students; (b) activities that can influence this students on developing learning motivation; and (c) reflections on the rules of formative and summative assessments, transforming their punitive aspect into a mediation form in the composition of students' final grades.

Keywords: Blended learning, online forums, peer instruction, Likert-type scale.

\section{Introdução}

Com o nascimento da sociedade digital a comunicação entre professores e alunos é ressignificada. O que antes era apenas quadro, caderno e oralidade, transforma-se em lousa eletrônica, tablet e videoaulas. A evolução tecnológica revela inovações metodológicas que promovem o protagonismo do aluno no processo de aprendizagem. Novos paradigmas e estratégias educacionais viabilizam espaços pedagógicos no ambiente virtual. Nos cursos superiores a realidade do ensino híbrido, cada vez mais presente, transfere o papel do professor, antes visto como centro do saber, para o papel de moderador e organizador de atividades pedagógicas que proporcionem ao estudante tornar-se responsável pelo seu aprendizado [1]. A Peer Instruction (PI), metodologia de ensino ativa centrada no estudante vem ganhando destaque internacional por sua capacidade de envolver ativamente os estudantes, intensificando a aprendizagem conceitual, e desenvolvendo habilidades sociais e cognitivas [2, [3].

\footnotetext{
*Endereço de correspondência: fmonteiro@unb.br
}

A comunicação dialogada nos fóruns on-line se apresenta como nova forma de construção coletiva de conhecimento individual e desenvolvimento de habilidade 4. Professores procuram se adaptar à nova realidade da chamada sociedade híbrida, aproveitando recursos disponíveis livremente na web [5]. A aprendizagem autorregulada pelos estudantes, entendida como a capacidade deles próprios gerirem seus progressos, suas estratégias e obstáculos diante das tarefas, tem chamado atenção de pesquisadores e pessoas ligadas à educação, por oferecer oportunidades e resultados positivos para e pelos estudantes, desenvolvendo a autonomia [6. No ensino de Física o reconhecimento de que a combinação simples de aulas expositivas e sessões de laboratório não garantem que os alunos desenvolvam compreensão profunda de conceitos críticos, têm feito com que, em muitas faculdades e universidades, o Sistema Tradicional Expositivo (STE) fosse modificado para permitir que os estudantes tenham papel mais ativo na aprendizagem [7 9].

Nesse sentido, em 2010 iniciou-se no Instituto de Física da UnB um processo de unificação das disciplinas básicas de Física 1 de 18 cursos diferentes. No primeiro 
momento, a sistemática das disciplinas unificadas consistiu basicamente na adoção de um mesmo plano de ensino, mesmo cronograma de aulas expositivas, e aplicação da mesma avaliação presencial a todos os alunos. O ambiente Moodle foi utilizado como apoio pedagógico, no sentido de facilitar o acesso a textos e listas de exercícios em pdf's, bem como para oferecer comunicados gerais. Nos semestres seguintes pequenos experimentos foram realizados. Observou-se a existência de grande correlação entre as notas médias de provas dos estudantes em cada curso com as respectivas notas de corte no vestibular. Constatou-se que no modelo de aulas puramente expositivas, os professores tinham pouca ou quase nenhuma influência sobre o desempenho dos estudantes nas provas, e que alguns estudantes entravam na universidade com formação insuficiente para enfrentar as disciplinas básicas da Física, tendo sido classificados como menos proficientes [10]. Nas avaliações, as vantagens e desvantagens do uso de questões de julgamento, bem como a inserção da penalização de respostas erradas como mecanismo de ajuste sobre o acerto casual também foram investigadas, revelando que o aumento do poder discriminativo da avaliação supera a redução da confiabilidade do escore, quando se aplica a penalização de resposta errada em itens de julgamento [11].

Seguindo esta tendência, no segundo semestre de 2018 um novo experimento foi realizado nas disciplinas unificadas de Física 1 de 18 cursos diferentes, envolvendo 665 estudantes. Sem eliminar o ensino presencial expositivo, foi adicionada à disciplina uma experiência online, na qual os estudantes contaram com o apoio de roteiros de estudos, sugerindo leituras e videoaulas, testes tipo-T, para acompanhamento dos conteúdos, testes tipo-M, para verificação de aprendizagem, e fóruns online, para interações dialogadas estudante-estudante e estudante-monitor. Além disso, as avaliações presenciais, com poder classificatório, foram transferidas para as duas últimas semanas do curso. A experiência revelou novas possibilidades para a realidade dos cursos de alta demanda. O suporte pedagógico on-line, com verificação sistemática de aprendizagem e estímulo à comunicação dialogada, ofereceu mais protagonismo aos estudantes e mais interação.

O objetivo deste trabalho é apresentar uma análise da percepção dos estudantes sobre esta experiência de ensino híbrido, com relação à organização da disciplina, ao potencial de aprendizagem e à qualidade do sistema de avaliação. Um questionário de opinião com proposições afirmativas sobre os temas foi aplicado separadamente para estudantes reprovados e aprovados na disciplina, revelando boa concordância com as proposições apresentadas, e indicando que, na opinião dos estudantes, os fóruns on-line foram importantes no processo de aprendizagem. Contudo, apontou também a necessidade de intervenções que possam: (a) promover a inclusão dos estudantes menos proficientes; (b) desenvolver a motivação para o aprendizado; e (c) transformar o caráter punitivo das avaliações formativas e somativas em uma forma de mediação na composição das notas ou menções finais dos estudantes.

\section{Referenciais Teóricos}

\subsection{Instrução entre os pares}

Popularizado na década de 1990 pelo professor de Física Eric Mazur, da Universidade de Harvard, a Instrução entre os Pares, ou Peer Instruction (PI), é uma metodologia ativa de aprendizagem que se contrapõe ao STE. O professor não é mais ser centro do saber, e os estudantes abandonam o papel de simplesmente absorver a instrução e as reproduzir nos exames. Ela subverte na dinâmica da sala, propondo aos estudantes se auxiliem mutuamente, e deixando ao professor o papel de simples mediador. Na PI ao invés de realizar poucas perguntas a alguns estudantes motivados durante uma aula expositiva, todos os estudantes são envolvidos em uma dinâmica que estabelece o foco da ação educativa centrada no estudante, e não no professor [12. Na PI a progressão em cada aula depende do resultado do feedback dos estudantes, em tempo real, para questões conceituais e testes de múltipla escolha. Ela tem mostrado efetividade em ambientes universitários, principalmente para estudantes com menos conhecimentos prévios, que apresentam melhor aprendizagem conceitual e habilidades para resolver problemas, quando comparados ao STE [13].

\subsection{Comunicação dialogada em fóruns on-line}

No ensino mediado pela internet, a comunicação dialogada em fóruns on-line estabelece uma importante variável na aprendizagem colaborativa. O termo diálogo, no sentido da interação intencional, construtiva e valorizada pelas partes que o estabelecem, favorece o desenvolvimento de habilidades cognitivas e atitudes colaborativas 14. Na mediação simbólica, que se dá nas interações on-line, o discurso muito menos linear e a possibilidade de consulta a outras pessoas ou fontes bibliográficas, influenciam a comunicação entre os estudantes e a construção social do conhecimento [15]. A forma como os tutores ou professores intervêm nas discursões online ajudam a direcionar, definir limites e estimular o envolvimento dos estudantes [16].

\subsection{Avaliação formativa e somativa}

A avaliação é um processo que deve ser contínuo e personalizado, com objetivo não somente de avaliar a aprendizagem, mas também a metodologia e o ambiente [17. De acordo com Bloom [18, o caráter controlador da avaliação formativa permite avaliar o progresso do estudante ao longo de cada etapa de aprendizado, enquanto o caráter classificatório da avaliação somativa, geralmente 
aplicada ao final de um curso ou módulo de ensino, estabelece uma métrica de aprendizado normalmente traduzida por uma nota ou menção. Para Chizzotti [19], o uso de avaliações meramente somativas apresenta equívocos discriminatórios, além do viés punitivo das notações meritocráticas. E sustenta que somente a avaliação formativa pode garantir o direito de aprender. Modernamente, o uso de softwares adequados, permite que a avaliação formativa realizada no ambiente on-line tenha feedback imediato e a possibilidade de múltiplas tentativas. Tais características podem aliviar as tensões típicas de um processo de avaliação e motivar os estudantes a continuar em frente. Contudo, traz também preocupações relativas à confiabilidade relacionada ao atendimento dos propósitos pretendidos [19].

\subsection{Ensino híbrido}

O ensino híbrido, ou blended learning, uma das grandes tendências da educação do século 21, pressupõe a combinação de espaços, tempos, atividades e metodologias. Integra a educação às TDICs, combinando a sistemática de ensino presencial com a proposta de ensino on-line. Propõe o trabalho colaborativo e proporciona momentos pedagógicos que se estendem para além das salas de aula presenciais [20]. O uso dos fóruns on-line possibilita a comunicação dialogada assíncrona entre os estudantes, revelando uma mudança de paradigma sobre a construção de conhecimento e promovendo ações integradoras que contribuem para a consolidação do uso das TDICs como apoio à educação [14. As possibilidades introduzidas pela internet e o acesso a softwares de fácil utilização, como o MOODLE, permitem a implementação de sistemáticas de ensino on-line como forma de limitar as limitações do STE. Nestes ambientes on-line a interação entre os alunos apresenta forte vertente colaborativa, revelando novas possibilidades de comunicação, partilha, interação e autonomia, responsabilizando os alunos pelo seu processo de aprendizagem [21].

\subsection{Aprendizagem autorregulada pelos estudantes}

A aprendizagem regulada pelo próprio estudante, compreendida como a interação de variáveis pessoais (conhecimento, competências e motivações), necessárias ao planejamento, a organização, ao controle e a avaliação dos processos adaptados, dos resultados atingidos e das variáveis contextuais, estimulam e dão ao estudante oportunidade de agir de forma intencional e estratégica 22. A autorregulação da aprendizagem implica refletir sobre a utilização de recursos educativos para gerir o que, quando, como, com quem e por que aprender. Nesse sentido, a literatura tem sugerido que a plataforma Moodle facilita a orientação dos conteúdos, o estudo autônomo, a melhoria do aproveitamento acadêmico e a motivação [23]. O Moodle oferece ferramentas para que o estudante auto regule a sua aprendizagem individualmente ou em colaboração com seus pares, se responsabilizando pela aquisição de hábitos e métodos, permitindo o desenvolvimento da autorregulação da aprendizagem [24].

\section{Descrição da Experiência de Ensino Híbrido}

Com o uso do ambiente virtual MOODLE (Modular Object-Oriented Dynamic Learning Environment), 704 estudantes de Física 1 participaram de uma experiência de ensino híbrido, adaptada para a sistemática de ensino unificado, já relatada em trabalhos anteriores [10, 11, na qual todas as turmas atenderam ao mesmo plano de ensino e às mesmas avaliações. $\mathrm{O}$ conteúdo da disciplina foi dividida em 12 módulos de ensino, em ambos os ambientes de aprendizagem, presencial e on-line.

Foi adotado como referência básica a $12^{\mathrm{a}}$ edição do livro Física 1 - Mecânica dos autores Young, H. D e Freedman, R. A. Os módulos de ensino foram divididos em: (1) unidades e grandezas físicas; (2) movimento retilíneo; (3) vetores; (4) movimento em duas e três dimensões; (5) leis de Newton; (6) aplicação das leis de Newton; (7) trabalho e energia cinética; (8) conservação de energia; (9) momento linear e impulso; (10) colisões; (11) rotação de corpos rígidos; (12) dinâmica de rotações.

Todos os monitores escolhidos cursaram Física 1 nos semestres anteriores, na sistemática das disciplinas unificadas, tendo obtido nota final de aprovação entre 7 e 10. Eles foram orientados a oferecer dicas que estimulassem os alunos a refletirem um pouco mais sobre um dado problema, ao invés de apresentar respostas prontas às dúvidas indicadas pelos alunos. Cada um dos 6 monitores ficou responsável por apenas dois módulos de ensino durante todo o semestre, facilitando o envolvimento e a interação com os estudantes.

No ambiente presencial as aulas permaneceram com o caráter predominantemente expositivo, instrucional e motivacional. Os professores ditaram o ritmo do curso, concluindo um módulo de ensino por semana, independentemente do desempenho dos estudantes.

No ambiente on-line foi oferecido como suporte roteiros de estudo, avaliações on-line e fóruns on-line. Os estudantes ditaram o ritmo de cada módulo do curso, respeitando, no entanto, uma data final limite e somente puderam avançar após demonstrar um desempenho mínimo em cada módulo.

Os roteiros de estudo indicaram aos estudantes videoaulas específicas sobre os temas de cada módulo, a leitura de tópicos do livro texto, o estudo de exercícios resolvidos e comentados pelo autor do livro texto, e a realização dos testes tipo- $\mathrm{T}$, como ferramenta de auto avaliação de aprendizagem. Estes testes foram opcionais, não exigiram rendimento mínimo, trataram de tópicos pontuais dentro de um módulo e puderam ser feitos múltiplas vezes. Ao final de cada módulo os roteiros indicaram a realização do respectivo teste tipo-M, para 
verificação de aprendizagem de todos os tópicos estudados no módulo. Estes testes foram obrigatórios e exigiram rendimento mínimo de $90 \%$, contudo, puderam ser feitos múltiplas vezes dentro de um prazo de até 5 semanas, e suas questões puderam ser discutidos nos fóruns on-line e nas aulas presenciais.

Os estudantes iniciaram o curso pelo módulo 0 , no qual foram solicitados a estudar o plano de ensino e, em seguida, fazer um teste tipo-M sobre os objetivos da disciplina, metodologia, critérios de avaliação, regras de aprovação etc. Ao obter o rendimento mínimo de $90 \%$ o módulo 0 foi considerado concluído (ou completo) e, automaticamente, o módulo 1 foi liberado. Nesta sistemática, os estudantes seguiram todos os módulos em sequência, e puderam avançar para o seguinte cada vez que o anterior fosse considerado completo.

Em cada módulo on-line os estudantes foram estimulados a participar da monitoria virtual (fórum on-line específico do módulo), num processo de comunicação dialogada e assíncrona, sempre mediados por um monitor dedicado ao módulo. Alguns estudantes apresentaram dúvidas referentes às leituras, aos exercícios resolvidos pelo autor, e aos testes tipo-T e tipo-M, enquanto outros se empenharam em auxiliar os colegas. Os estudantes que participaram de todos os fóruns on-line até o módulo 12 receberam o emblema "Onipresente-Física 1". Como o objetivo central da experiência foi observar o protagonismo dos estudantes ao seguir os roteiros de estudo, cumprir as atividades propostas nos devidos tempos e se manifestar nos fóruns, não houve a preocupação em identificar os estudantes que participaram dos fóruns para posterior comparação de desempenho com os alunos que não participaram. Contudo, pelo acompanhamento das postagens e comentários ficou evidente que a participação dos estudantes na monitoria virtual ficou mais bem distribuída ao longo do semestre e atraiu mais estudantes que a monitoria presencial dos semestres anteriores, nas quais era frequente a presença dos alunos apenas às vésperas das provas. Além disso, o resultado do questionário aplicado aos estudantes apontou (veja seção 5) que, na opinião deles, os fóruns foram importantes para a aprendizagem.

As avaliações on-line foram distribuídas em diagnósticas (testes tipo-T, duas por módulo, totalizando 24) e formativas (testes tipo-M, uma por módulo, totalizando 12), ambas com feedback imediato e com possibilidade de múltiplas tentativas. A primeira - com função analítica -, permitiu aos estudantes reconhecer elementos que precisavam ser revisitados, e a segunda com função controladora - estabeleceu exigência de rendimento mínimo de $90 \%$ para que fosse possível seguir em frente. Neste último caso, contudo, além do prazo longo de 1 a 5 semanas para as avaliações formativas, os estudantes foram estimulados a compartilhar suas dúvidas na monitoria virtual, ajudar a dirimir dúvidas de outros estudantes, consultar outros materiais didáticos e solicitar apoio dos professores.
As avaliações presencias (duas no total) foram aplicadas apenas nas duas últimas semanas do curso e, com o objetivo de desmobilizar práticas de estudo somente às vésperas das avaliações presenciais, apenas os estudantes que completaram ao menos 9 dos 12 módulos de ensino on-line puderam fazê-las. Todos os estudantes que não completaram o Módulo 9 até a data prevista (aproximadamente $16 \%$ ) ficaram automaticamente reprovados e não fizeram as avaliações presenciais finais. Este número não foi tão discrepante dos semestres anteriores, nos quais aproximadamente $19 \%$ dos alunos simplesmente não compareciam às avaliações finais, por não terem mais chances matemáticas de aprovação.

Para ser aprovado o estudante precisou obter em qualquer uma das duas avaliações presenciais nota igual ou superior a 5,0, e cada um dos estudantes aprovados compôs sua nota final com a maior dentre as duas notas obtidas nas avaliações presencias, acrescida de 0,25 pontos por cada módulo completo do 9 ao 12 . A razão para não levar em conta os módulos anteriores ao 9 , no acréscimo dos pontos, foi para evitar que um estudante fosse aprovado, mesmo tendo obtido 2,0 ou 3,0 como maior nota nas avaliações presencias. Neste caso, vale ressaltar que, observando os logs do sistema ao final do semestre, notamos que alguns estudantes, estavam claramente tentando mapear o banco de questões até o módulo 9. Os registros do Moodle indicaram que, em alguns casos, os testes tipo-M foram realizados múltiplas vezes e submetidos em um intervalo curtíssimo (menos de 2 min entre um e outro). Ao conversarmos com alguns estudantes ficamos sabendo que estes testes com as respectivas respostas, devolvidos pelo Moodle como feedback ao estudante, foram salvos no PC e posteriormente compartilhados pela internet.

Embora todos os estudantes que fizeram a provas presencias tenham completado $75 \%$ do curso (9 de 12 módulos) com rendimento excelente, ou seja obtiveram ao menos 9 de 10 pontos nos testes-M de cada módulo, apenas $62 \%$ deles tiveram sucesso, ou seja, obtiveram ao menos 5 de 10 pontos em uma das duas avaliações presenciais.

Na comparação com a média dos semestres anteriores ${ }^{1}$ o percentual de aprovação na disciplina teve um aumento de $27 \%$ (de $41 \%$ para $52 \%$ ) e o percentual de trancamento teve uma redução de $15 \%$ (de $19 \%$ para $16 \%$ ). Entre os estudantes que permaneceram no curso até o final, ou seja, desconsiderando os que trancaram, o percentual de aprovação foi de $51 \%$, na média dos semestres anteriores, para $62 \%$, revelando um aumento de $22 \%$.

Cada avaliação presencial foi composta de 12 questões, sendo uma para cada um dos 12 módulos de ensino. Foram explorados: conceitos, interpretação de textos, interpretação de gráficos, habilidades numéricas e habilidades analíticas. As questões foram distribuídas em itens

\footnotetext{
1 Para a média dos semestres anteriores foram levados em conta todos os semestres de 2014 a 2017.
} 
dicotômicos do tipo $\mathrm{V} / \mathrm{F}$, múltipla escolha e numérica. As correções foram automatizadas com uso de programa específico desenvolvido em python, e as revisões de prova foram feitas coletivamente pelos estudantes nos fóruns de dúvida das provas, onde cada um dos itens da prova puderam ser refeitos, discutidos e reavaliados por um prazo de até três dias. Os fóruns das provas foram mediados pelos professores que elaboraram as provas. Ao final, os estudantes puderam propor alterações de gabarito, quando necessário, e somente então, as provas foram corrigidas. Este procedimento teve o objetivo de dar publicidade e objetividade ao processo de revisão de provas, com participação ativa e coletiva dos estudantes, além de permitir que eles aprendessem com os próprios erros, auxiliados pelos pares.

Com relação ao protocolo das provas presenciais, elas foram aplicadas a todos os estudantes ao mesmo tempo, sempre aos sábados. Ao final de cada prova, apenas os cartões-respostas foram entregues, e os estudantes saíram com as provas impressas. Uma hora após o término oficial de cada prova, o fórum da prova foi aberto, iniciando as discussões, que duraram até três dias. Nesses fóruns foram identificado três grupos principais de interagentes: (i) os que se posicionaram no sentido de tentar compreender como resolver uma questão que não havia obtido sucesso; (ii) os que haviam tido sucesso numa questão e se prontificaram a auxiliar outros; e (iii) os que simplesmente tentaram a todo custo encontrar meios para propor anulação de qualquer questão, numa tentativa clara de obter vantagem indevida. Estes últimos, algumas vezes, faltaram com o respeito, e o professor responsável pelo fórum de provas teve que intervir, deletando comentários inadequados e enviando mensagens particulares com orientações sobre as boas práticas no uso dos fóruns on-line.

\section{Metodologia de Pesquisa}

\subsection{Escala tipo-likert}

A escala tipo-Likert foi desenvolvida por Rensis Likert em 1932 para quantificar opiniões - ou atitudes -, e consiste em desenvolver um conjunto de proposições a respeito de um construto para em seguida, avaliar o grau de concordância dos respondentes [25]. Ela faz uso de diferenciais semânticos que variam qualitativamente em grau, desde o mais baixo Discordo Totalmente (DT) até o mais alto Concordo Totalmente (CT), podendo ser simétrica, com número ímpar de pontos e a neutralidade - Não Concordo Nem Discordo (NCND) exatamente entre os dois extremos, ou assimétrica, com número par de pontos, não oferecendo a opção de neutralidade e forçando os respondentes a escolher um dos lados [26]. Os valores numéricos atribuídos às respostas refletem a força e a direção da opinião dos respondentes em relação às proposições. A principal vantagem desse tipo de escala é a simplicidade de construção e a possibilidade de se incluir itens, ou proposições, diretamente relacionadas ao que se deseja avaliar. Por outro lado, a principal desvantagem está no fato de possuir natureza estritamente ordinal e, nesse sentido, as estatísticas descritivas ficam reduzidas, e geralmente são recomentadas, moda ou mediana para medidas de tendência central, frequência para medidas de variabilidade, e Qui-quadrado para medidas aderência e associação [25, 27, 28].

\subsection{Descrição da metodologia}

A pesquisa descrita neste artigo é do tipo qualitativa e de caráter descritivo. A análise de dados foi feita a partir de uma pesquisa de opinião construída no formato de escala tipo-Likert. Para a análise da percepção dos estudantes, foi escolhido o formato de escala de 5 pontos por apresentar nível de confiabilidade adequado e se ajustar melhor aos respondentes com diferentes níveis de habilidades. Neste caso, o diferencial semântico foi estabelecido como: 1-Discordo totalmente; 2-Discordo parcialmente; 3-Não discordo nem concordo; 4-Concordo parcialmente; 5-Concordo totalmente. O grau de concordância com a proposição (GCp) dos itens categóricos foram interpretados segundo o protocolo apresentado no quadro 1 conforme sugerido por James A. Davis [29].

A pesquisa de opinião foi aplicada no MOODLE e os estudantes foram divididos em dois grupos de respondentes: aprovados e reprovados.

As 15 proposições afirmativas do questionário de opinião foram divididas nas duas categorias abaixo:

Categoria 1 - Organização e potencial de aprendizagem

1. O roteiro de estudo foi útil na orientação dos estudos;

2. O livro recomendado é de fácil compreensão e é suficiente para acompanhar o curso;

3. As videoaulas foram importantes na melhora do aprendizado;

4. Os fóruns de dúvidas (monitoria virtual) presentes em cada módulo do MOODLE foram úteis para orientar o aprendizado;

5. Me senti motivado pela disciplina e me apliquei adequadamente aos estudos;

Quadro 1: Interpretação do GCp.

\begin{tabular}{|l|l|}
\hline Forte concordância & {$[90 ; 100]$} \\
\hline Concordância substancial & {$[80 ; 90]$} \\
\hline Concordância moderada & {$[70 ; 90]$} \\
\hline Concordância baixa & {$[60 ; 80]$} \\
\hline Concordância desprezível & {$[50 ; 60]$} \\
\hline Discordância desprezível & {$[40 ; 50]$} \\
\hline Discordância baixa & {$[30 ; 40]$} \\
\hline Discordância moderada & {$[20 ; 40]$} \\
\hline Discordância substancial & {$[10 ; 20]$} \\
\hline Forte discordância & {$[0 ; 10]$} \\
\hline
\end{tabular}

Revista Brasileira de Ensino de Física, vol. 43, e20200315, 2021 
6. A disciplina unificada é organizada e as informações relevantes são apresentadas de forma clara e acessível;

7. O professor da turma no qual estou matriculado foi pontual, assíduo e apresentou o conteúdo completo, conforme o cronograma;

8. O professor da turma na qual estou matriculado tem boa didática, é motivador e acessível;

9. A coordenação da unificação atua de maneira justa, transparente e responde rapidamente às solicitações dos alunos;

Categoria 2 - Qualidade do sistema de avaliação:

10. Os testes tipo $\mathrm{T}$ (avaliações diagnósticas on-line) nos diversos módulos do MOODLE são úteis como atividade para organizar os estudos e preparar-se para os testes tipo M (avaliações formativas online);

11. Os testes tipo M (avaliações formativas on-line) nos diversos módulos do MOODLE são um recurso importante, seja para ajudar a manter o ritmo de estudo, para ajudar a consolidar o aprendizado, ou ajudar a auto avaliar a aprendizagem;

12. O nível de cobrança das provas (avaliações somativas presenciais) é compatível com nível de conhecimento que o aluno deve possuir para ser aprovado na disciplina;

13. Quanto maior o domínio do conteúdo do aluno, maior sua nota nas provas da disciplina;

14. A prova (avaliação somativa presencial) avalia os diferentes aspectos relevantes à aprendizagem da disciplina (análise de conceitos, análise de situações-problema, cálculos algébricos e cálculos numéricos);

15. A revisão de prova (avaliação somativa presencial) via fórum esclarece as dúvidas dos alunos e atende de maneira justa às suas demandas.

\section{Análise dos Resultados}

A pesquisa de opinião foi autopreenchida pelos respondentes e a coleta de dados foi realizada pela internet por intermédio do MOODLE. Ela foi encaminhada a todos os estudantes de Física 1 do segundo semestre de 2018 (2018-2), que permaneceram no curso até o final, representando uma população de 384 estudantes reprovados e 207 estudantes aprovados. A amostra de respondentes correspondeu a $100(26 \%)$ estudantes reprovados, e 60 (29\%) estudantes aprovados. A generalização dos resultados a partir desses percentuais de participação deve ser adotada com cautela e interpretada como resultados preliminares. Contudo, apresenta potencial de aplicação, como hipótese inicial de trabalho, em estudos de maior amplitude e com amostras mais representativas.

As Tabelas 1 e 2 apresentam os resultados da pesquisa de opinião, organizando os dados nos grupos: aprovados e reprovados, e organizando as proposições afirmativas nas classes: concordância e discordância. Os dados entre parênteses referem-se aos valores esperados, conforme a hipótese (nula) Ho que pressupões a independência entre as variáveis de grupo e de classe.

A qualidade da pesquisa de opinião foi validada por um teste de aderência (qui-quadrado) ao nível de significância de 1\%, apresentando evidências estatísticas de que as respostas não foram aleatórias.

Além disso, em ambas as tabelas a hipótese nula (Ho) da independência entre as variáveis de grupo e as variáveis de classe foi verificada por um teste de contingência (qui-quadrado) ao nível de significância de $1 \%$. $\mathrm{O}$ resultado nos fez rejeitar a hipótese nula, revelando evidencias estatísticas de que, apesar da presença maciça da palavra concordância em ambos os grupos das duas tabelas, os estudantes aprovados foram mais propensos a concordar com as proposições afirmativas das categorias 1 e 2 que os reprovados.

\subsection{Organização e potencial de aprendizagem}

Na Tabela 1 é possível observar, na coluna que apresenta a interpretação do GCp, que das 9 proposições afirmativas representativas da categoria 1 - organização e potencial de aprendizagem -, 8 apresentaram concordância em ambos os grupos - aprovados e reprovados -, diferindo apenas no grau ou nível de concordância. A única exceção foi o item 9, que apontou uma discordância baixa. Este item se refere a atuação da coordenação que, na opinião dos estudantes, foi injusta, não transparente e não atendeu às solicitações dos alunos. De fato, a maior demanda dos estudantes recebida pela coordenação ao longo do semestre, seja presencialmente, seja por e-mail, foi pela liberação das datas limites das avaliações somativas on-line (testes tipo-M). Como essas demandas não foram atendidas, a coordenação foi frequentemente considerada injusta. Neste caso, é importante considerar que foi dada aos estudantes a flexibilidade de feedback imediato, múltiplas tentativas, prazo longo (de 1 a 5 semanas), auxílio da monitoria virtual e apoio dos professores. Mas, apesar disso, alguns estudantes se aproveitaram dessas flexibilidades para tentar mapear o banco de questões do sistema MOODLE, enquanto outros simplesmente deixaram para realizar as referidas avaliações na data limite de encerramento. Portanto, se por um lado, a existência das datas limites traz um caráter punitivo para as avaliações formativas on-line, por outro, a liberação completa traria pouco ou nenhum benefício para aqueles estudantes que tiveram por hábito deixar essas avaliações para o último momento. Uma possível solução seria estabelecer uma segunda data limite para cada avaliação on-line, vinculada a algum tipo de compromisso extra do estudante.

No ambiente presencial, o item categórico 7, referente ao conteúdo do curso e ao papel do professor, apresentou concordância substancial no grupo 2 e moderada no grupo 1. Este resultado sugere que, apesar de se 
Tabela 1: Análise do grau de concordância com as proposições GCp referentes à categoria 1 - Organização e potencial de aprendizagem - . Os dados foram obtidos de uma pesquisa de opinião na qual o diferencial semântico seguiu a escala do tipo Likert no formato de 5 pontos. A amostra de respondentes teve a participação de $26 \%$ da população de estudantes reprovados e $29 \%$ da população de estudantes aprovados. A hipótese nula Ho pressupõe a independência entre as variáveis de grupo (aprovado e reprovado) e as variáveis de classe (concordância e discordância).

\begin{tabular}{|c|c|c|c|c|c|}
\hline & \multicolumn{5}{|c|}{ CATEGORIA 1 - ORGANIZAÇÃO E POTENCIAL DE APRENDIZAGEM } \\
\hline & \multicolumn{5}{|c|}{$\begin{array}{c}\text { Tabela de valores observados } \\
\text { (valores esperados sob Ho entre parênteses) }\end{array}$} \\
\hline \multirow{10}{*}{ 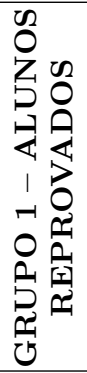 } & PROPOSIÇÕES & CONCORDÂNCIA & DISCORDÂNCIA & GCp & INTERPRETAÇÃO \\
\hline & 1 & $53,5(42,5)$ & $44,5(42,5)$ & $55 \%$ & concordância desprezível \\
\hline & 2 & $22(14)$ & $8(14)$ & $73 \%$ & concordância moderada \\
\hline & 3 & $60(42)$ & $36(42)$ & $63 \%$ & concordância baixa \\
\hline & 4 & $76(40,5)$ & $21(40,5)$ & $78 \%$ & concordância moderada \\
\hline & 5 & $57(43)$ & $41(43)$ & $58 \%$ & concordância desprezível \\
\hline & 6 & $55(44,5)$ & $44(44,5)$ & $56 \%$ & concordância desprezível \\
\hline & 7 & $74,5(44)$ & $22,5(44)$ & $77 \%$ & concordância moderada \\
\hline & 8 & $58,5(42)$ & $36,5(42)$ & $62 \%$ & concordância baixa \\
\hline & 9 & $39(37,5)$ & $54(37,5)$ & $42 \%$ & discordância baixa \\
\hline \multirow{10}{*}{ 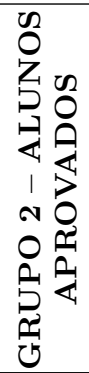 } & PROPOSIÇÕES & CONCORDÂNCIA & DISCORDÂNCIA & GCp & INTERPRETAÇÃO \\
\hline & 1 & $47(26)$ & $11(26)$ & $81 \%$ & concordância substancial \\
\hline & 2 & $46(25)$ & $10(25)$ & $82 \%$ & concordância substancial \\
\hline & 3 & $30,5(20,5)$ & $19,5(20,5)$ & $61 \%$ & concordância baixa \\
\hline & 4 & $41(24)$ & $15(24)$ & $73 \%$ & concordância moderada \\
\hline & 5 & $39(24,5)$ & $20(24,5)$ & $66 \%$ & concordância baixa \\
\hline & 6 & $36,5(25)$ & $20,5(25)$ & $64 \%$ & concordância baixa \\
\hline & 7 & $47(25)$ & $9(25)$ & $84 \%$ & concordância substancial \\
\hline & 8 & $35(23,5)$ & $22(23,5)$ & $61 \%$ & concordância baixa \\
\hline & 9 & $23(21,5)$ & $28(21,5)$ & $45 \%$ & discordância baixa \\
\hline
\end{tabular}

Tabela 2: Análise do grau de concordância com as proposições GCp referentes à categoria 2 - Qualidade do sistema de avaliação Os dados foram obtidos de uma pesquisa de opinião na qual o diferencial semântico seguiu a escala do tipo Likert no formato de 5 pontos. A amostra de respondentes teve a participação de $26 \%$ da população de estudantes reprovados e $29 \%$ da população de estudantes aprovados. A hipótese nula Ho pressupõe a independência entre as variáveis de grupo (aprovado e reprovado) e as variáveis de classe (concordância e discordância).

\begin{tabular}{|c|c|c|c|c|c|}
\hline & \multicolumn{5}{|c|}{ CATEGORIA 2 - QUALIDADE DO SISTEMA DE AVALIAÇÃO } \\
\hline & \multicolumn{5}{|c|}{$\begin{array}{c}\text { Tabela de valores observados } \\
\text { (valores esperados sob Ho entre parênteses) }\end{array}$} \\
\hline \multirow{7}{*}{ 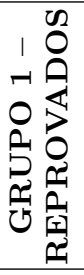 } & PROPOSIÇÕES & CONCORDÂNCIA & DISCORDÂNCIA & GCp & INTERPRETAÇÃO \\
\hline & 10 & $60(27)$ & $24(27)$ & $71 \%$ & concordância moderada \\
\hline & 11 & $65(46)$ & $33(46)$ & $66 \%$ & concordância baixa \\
\hline & 12 & $43(42)$ & $53(42)$ & $45 \%$ & discordância baixa \\
\hline & 13 & $56,5(44)$ & $42,5(44)$ & $57 \%$ & concordância desprezível \\
\hline & 14 & $61(44)$ & $37(44)$ & $62 \%$ & concordância baixa \\
\hline & 15 & $49,5(36)$ & $43,5(36)$ & $53 \%$ & concordância desprezível \\
\hline \multirow{7}{*}{ 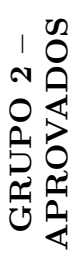 } & PROPOSIÇÕES & CONCORDÂNCIA & DISCORDÂNCIA & GCp & INTERPRETAÇÃO \\
\hline & 10 & $44,5(27)$ & $12,5(27)$ & $78 \%$ & concordância moderada \\
\hline & 11 & $46,5(25)$ & $10,5(25)$ & $82 \%$ & concordância substancial \\
\hline & 12 & $38,5(26)$ & $18,5(26)$ & $68 \%$ & concordância baixa \\
\hline & 13 & $45,5(27,5)$ & $12,5(27,5)$ & $78 \%$ & concordância moderada \\
\hline & 14 & $47(25)$ & $11(25)$ & $81 \%$ & concordância substancial \\
\hline & 15 & $33,5(21,5)$ & $16,5(21,5)$ & $67 \%$ & concordância baixa \\
\hline
\end{tabular}

tratar de uma disciplina de alta demanda envolvendo várias turmas de diferentes cursos, a organização do curso no formato de ensino híbrido estimulou os professores a apresentar o conteúdo de forma completa, conforme cronograma, e demonstrarem assiduidade e pontualidade, revelando uma característica positiva da metodologia.
Contudo, o item categórico 8, referente à didática, motivação e acessibilidade do professor, apresentou concordância baixa em ambos os grupos, apontando a necessidade de intervenção com atividades que possam motivar os professores a refletirem sobre suas práticas didáticas, tornando-os mais acessíveis e mais próximos dos alunos. 
No ambiente on-line, o item categórico 1, referente à importância do roteiro de estudos para orientação dos estudantes, revelou concordância substancial no grupo dos estudantes aprovados, e concordância desprezível no grupo dos estudantes reprovados. A diferença no nível de concordância entre os dois grupos sugere a necessidade de repensar os roteiros de estudo com estratégias que estimulem a inclusão dos estudantes menos proficientes. Por outro lado, o item 2, que afirma ser o livro texto de fácil compreensão e suficiente para acompanhar o curso, obteve concordância moderada em ambos os grupos, revelando bom potencial para ser mais explorado nos roteiros de estudos, tornando-se um dos possíveis elementos para estimular a inclusão dos estudantes menos proficientes.

O item categórico 3, referente às videoaulas, apresentou concordância baixa em ambos os grupos - aprovados e reprovados -, apontando a necessidade de intervenção. Alguns estudantes revelaram em conversa informal a preferência por videoaulas de 5 a 7 minutos ao invés das videoaulas de 50 minutos que foram sugeridas pelos roteiros de estudo.

O item categórico 4 , referente à utilidade da monitoria virtual para orientar o aprendizado, apresentou concordância moderada em ambos os grupos, revelando uma característica importante da nova metodologia em relação ao potencial de aprendizagem, que, mesmo sendo uma disciplina de alta demanda, permite a participação ativa dos estudantes numa interação entre pares, mediada por um monitor e de forma assíncrona no ambiente virtual. Nesse sentido, seria importante fomentar práticas que possam estimular ainda mais a participação dos estudantes na monitoria virtual, tornando-os mais ativos no processo de aprendizagem.

O item 5, referente aos estudantes terem se sentido motivados pela disciplina e terem se aplicado adequadamente aos estudos, apresentou concordância baixa no grupo 2 e concordância desprezível no grupo 1. Este resultado sugere a necessidade de se criar atividades que influenciem o estudante a desenvolver motivação para o aprendizado. Uma possibilidade seria aproveitar o potencial das monitorias virtuais, transformando-as em pequenas comunidades de investigações [30, 31].

\subsection{Qualidade do sistema de avaliação}

A Tabela 2 revela, em ambos os grupos, concordância em todos os itens categóricos, com exceção do item 12 , que apresentou discordância baixa entre os estudantes do grupo 1, e concordância baixa entre os estudantes do grupo 2. O item se refere à compatibilidades entre o nível da avaliações somativas presenciais e o nível de conhecimento que o estudante deve possuir para ser aprovado na disciplina. Contudo, é importante ressaltar que, sendo essa disciplina pré-requisito para outras, ela exige um nível mínimo de cobrança do qual não se pode evitar. De qualquer modo, esse resultado revela a necessidade de intervenções que possam motivar os estudantes e potencializar aprendizagem, além de intervenções que possam recuperar os estudantes reprovados. Nesse sentido, as reflexões já mencionadas sobre o roteiro de estudos, o livro texto e as comunidades de investigação, podem ser um ponto de partida para as futuras intervenções.

O item categórico 10, referente à utilidade das avaliações diagnósticas on-line como atividade de organização dos estudos, apresentou concordância moderada em ambos os grupos, revelando bom potencial para ser explorado como mecanismo de estímulo para inclusão dos estudantes menos proficientes.

$\mathrm{O}$ item categórico 11, que se refere às avaliações formativas como recurso importante para manter o ritmo de estudo e consolidar o aprendizado, teve concordância substancial no grupo 2, e concordância baixa no grupo 1. Este resultado sugere a necessidade de reflexão sobre estrutura das avaliações formativas, que apresente um aspecto mais motivador, e que estimule o estudante a ter maior envolvimento com a disciplina.

$\mathrm{O}$ item categórico 13 , referente à relação entre o domínio de conteúdo do estudante e a sua nota na avaliação somativa, apresentou concordância moderada no grupo 2 e concordância desprezível no grupo 1. Esse resultado, revela uma preocupação particular, haja visto que todos os estudantes que fizeram as avaliações somativas, foram aprovados com menção máxima em ao menos 9 das 12 avaliações formativas. Desse modo, ele apronta a necessidade de reflexão sobre as regras de composição das avaliações formativas e somativas, que possam transformar o aspecto punitivo em uma forma de mediação na composição das menções finais dos estudantes.

O item categórico 14, referente à composição das avaliações somativas presencias, apresentou concordância substancial no grupo 2 e concordância baixa no grupo 1 . Esse resultado sugere que, apesar da avaliação somativa presencial ter sido considerada difícil pelos estudantes, ela também foi considerada como apresentando boa qualidade. Contudo, a reflexão sobre outras abordagens para as avaliações somativas, como a possibilidade de recuperação para os estudantes menos proficientes, podem trazer benefícios à metodologia e aos estudantes.

$\mathrm{O}$ item categórico 15 , referente às demandas dos estudantes relativas à revisão das avaliações somativas presencias via fórum de dúvidas, apresentou concordância baixa no grupo 2 e concordância desprezível no grupo 1. Este resultado reforça a preocupação sobre o estudante ser reprovado no ambiente presencial, apesar de apresentar excelente desempenho no ambiente online. Neste sentido, as reflexões já mencionadas acima, que se referem ao potencial de motivação, mediação e inclusão dos estudantes menos proficientes também se aplicam a este item.

Em resumo, embora haja elementos que podem ser melhorados ou que precisam ser revistos, a análise do questionário de opinião revelou boa concordância dos 
estudantes em relação às proposições afirmativas sobre organização e potencial de aprendizagem e sobre a qualidade do sistema de avaliação, apresentando em ambas as categorias apenas uma discordância de nível baixo.

\section{Conclusão}

A análise da percepção dos estudantes sobre a experiência de aprendizagem híbrida, revelou vários aspectos positivos, mas também apontou algumas necessidades que merecem intervenções.

Apesar de se tratar de uma disciplina de alta demanda, a forma como a disciplina foi organizada, estimulou os professores a se preocuparem com o cumprimento da ementa e demonstrarem assiduidade e pontualidade, revelando uma característica positiva da metodologia. Contudo, a pesquisa também apontou a necessidade de intervenções que possam motivar os professores a refletirem sobre suas práticas didática, tornando-os mais acessíveis e mais próximos dos alunos.

Os roteiros de estudo e o livro texto foram apontados como suportes importantes para organização dos estudos, mas revelou a necessidade de articulações que possam estimular a inclusão dos estudantes menos proficientes.

As videoaulas, apesar de apresentar potencial para o aprendizado, foram avaliadas como sendo muito extensas - em torno de $50 \mathrm{~min}$-, e os estudantes manifestaram preferência por videoaulas mais curtas - 5 a $7 \mathrm{~min}-\mathrm{com}$ o conteúdo fragmentado em unidades menores.

As monitorias virtuais se revelaram importantes no processo de aprendizagem, permitindo que, mesmo sendo uma disciplina de alta demanda, pudesse haver a interação estudante-estudante e estudante-monitor em um ambiente dialogado de cooperação e investigação contribuindo para que os estudantes fossem mais ativos e responsáveis na construção do conhecimento individual e coletivo.

As avaliações formativas on-line foram apontadas como recurso importante para manter o ritmo de estudo e consolidar o aprendizado, mas revelaram a necessidade de reflexão sobre a sua estrutura, de modo que inspire motivação, e que estimule o estudante a ter maior envolvimento com a disciplina. As avaliações somativas presenciais, apesar de terem sido consideradas difíceis, foram reconhecidas por apresentarem boa qualidade em sua formulação. Entretanto, as regras de combinação dos desempenhos obtidos nas avaliações formativas e somativas apresentou a necessidade de serem revistas, no sentido de transformar o caráter punitivo que elas incorporam em uma forma de mediação pedagógica na composição das menções finais dos estudantes.

Em resumo, a análise da percepção dos estudantes, revelou boa aceitação sobre a experiência de ensino híbrida, com relação à organização, potencial de aprendizagem e qualidade do sistema de avaliação, com destaque positivo a interação dialogada nas monitorias virtuais. Contudo, apontou a necessidade de intervenções que possam dar à metodologia um caráter mais inclusivo e menos punitivo. Além disso, revelou a preocupação dos estudantes que, mesmo apresentando excelentes resultados no ambiente on-line, são reprovados no ambiente presencial, reforçando a necessidade de reflexões que possibilitem as atividades on-line mediar a composição das notas ou menções finais dos estudantes e de atividades que possam recuperar os estudantes reprovados.

\section{Agradecimentos}

A experiência de ensino híbrido relatada neste trabalho contou com o apoio dos professores e monitores designados às turmas dessa disciplina, aos quais eu agradeço em conjunto. Agradeço em especial aos professores Jorlandio F. Felix, Pedro H. O. Neto, Leonardo E de Sousa e Gabriela Possa que tiveram papel fundamental na discussão, planejamento e implementação de vários aspectos da mesma, e à técnica Simone B. Farias cuja dedicação foi fundamental para o sucesso da experiência.

\section{Referências}

[1] M.D.L.D.J. Peña e S.M. de M. Allegretti, Rev. Contemp. Educ. e Tecnol. 1, 97 (2012).

[2] M.G. Müller, I.S. Araujo, E.A. Veit e J. Schell, Rev. Bras. Ensino Física 39, 3 (2017).

[3] A.L. Rudolph, B. Lamine, M. Joyce, H. Vignolles e D. Consiglio, Phys. Rev. Spec. Top. - Phys. Educ. Res. 10, 1 (2014).

[4] M. Moreira, Actas del III Encuentro Internacional sobre Aprendizaje 1, 15 (2006).

[5] J. A. da S.P. Neto, Séries-Estudos - Pèriódico do Mesatrado em Educação da UCDB 1, 117 (2006).

[6] G.C. Punhagui e N.A. De Souza, Int. Educ. Stud. 6, 47 (2013).

[7] G.T. Aragon, S.A. Martinez, L. Bockorni e G. Giglio, Rev. Educ. Pública 1, 1 (2016).

[8] D.M.M. Leão, Cad. Pesqui. 1, 187 (1999).

[9] M.A. Ruiz-Primo, D. Briggs, H. Iverson, R. Talbot e L.A. Shepard, Science 331, 1269 (2011).

[10] B.A. Mello, Rev. Bras. Ensino Fis. 37, 1 (2015).

[11] F.F. Monteiro, C.B. Alves e B.A. Mello, Rev. Bras. Ensino Fis. 40, 1 (2018).

[12] C.H. Crouch e E. Mazur, Am. J. Phys. 69, 970 (2001).

[13] N. Lasry, E. Mazur e J. Watkins, Am. J. Phys. 76, 1066 (2008).

[14] http://www.abed.org.br/congresso2007/tc/5320073112 1PM.pdf

[15] F. Rezende e G.R.P.C. Queiroz, Ciência Educ. 15, 459 (2009).

[16] D. Nandi, M. Hamilton e J. Harland, Distance Educ. 33, 5 (2012).

[17] E. da S.G. de Oliveira, V.L. Cunha, A.P. da Encarnação, L. Santos, R.A. de Oliveira e R. da S. Nunes, Rev. Iberoam. sobre Calidad, Efic. y Cambio en Educ. 5, 39 (2007). 
[18] B.S. Bloom, J.T. Hastings e G.F. Madaus, Handbook on Formative and Summative Evaluation of Student Learning (McGraw-Hill, New York, 1971), $1^{\circ}$ ed.

[19] Z. Gaylard Baleni, Electron. J. e-Learning 13, 228 (2015).

[20] L. Bacich e J. Moran, Rev. Pátio 25, 45 (2015).

[21] E.S. Lisbôa, A.G. de Jesus, A.M.L.M. Varela, C.P. Teixeira e G.H.S. Coutinho, Educ. Formação Tecnol. 2, 44 (2009).

[22] L.G.L. Freire, Ciênc. cogn. 14, 276 (2009).

[23] A. Oliveira e E. Cardoso, Educ. Formação Tecnol. 2, 58 (2009).

[24] L.C. Winter, S. Kopeinik, D. Albert, A. Dimache, A. Brennan e T. Roche, Proc. - 2nd IIAI Int. Conf. Adv. Appl. Informatics, IIAI-AAI 2013 1, 203 (2013).

[25] M. Meireles, Rev. Da Micro E Pequena Empres. 14, 1 (2020).

[26] A. Joshi, S. Kale, S. Chandel e D. Pal, Br. J. Appl. Sci. Technol. 7, 396 (2015).

[27] C. Sanches et al., in EnEPQ, 1, 1, pp. 1-17, (2011).

[28] C. Sanches, M. Meireles e J.O. De Sordi, J. Ext. 50, 1 (2012).

[29] J.A. Davis, Levantamento de dados em sociologia: Uma análise estatística elementar (Zahar, Rio de Janeiro, 1976), $1^{\circ}$ ed.

[30] M. Lipman, Thinking in Education (Cambridge University Press, New York, 2020), $2^{\circ}$ ed.

[31] S.W. Martins, A.J. Mendes e A.D. Figueiredo, Rev. Iberoam. Tecnol. del Aprendiz. 5, 39 (2010). 